\title{
Radiographic Characteristics of Soft Tissue Calcification on Digital Panoramic Images
}

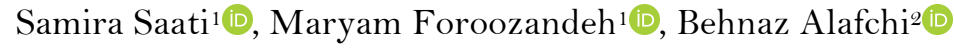

\begin{abstract}
${ }^{1}$ Department of Oral and Maxillofacial Radiology, Dental School, Hamadan University of Medical Sciences, Hamadan, Iran.

${ }^{2}$ Department of Biostatics, School of Public Health, Hamadan University of Medical Sciences, Hamadan, Iran.
\end{abstract}

Author to whom correspondence should be addressed: Maryam Foroozandeh, Department of Oral and Maxillofacial Radiology, Dental School, Hamadan University of Medical Sciences, Shahid Fahmideh Blvd, Hamadan, Iran. 6516647447. Phone: +989184400791. E-mail: f.maryam1991@gmail.com.

Academic Editors: Alessandro Leite Cavalcanti and Wilton Wilney Nascimento Padilha

Received: 01 July 2019 / Accepted: 20 March 2020 / Published: 14 April 2020

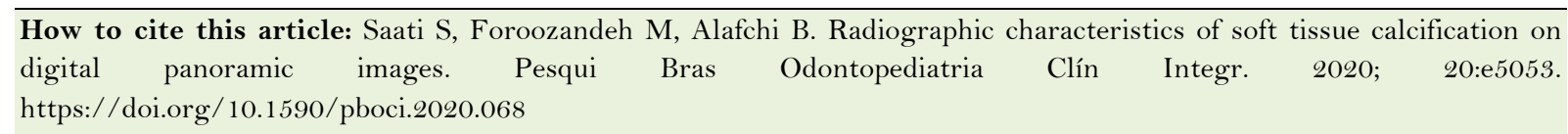

\begin{abstract}
Objective: To assess the prevalence of soft tissue calcifications and their panoramic radiographic characteristics. Material and Methods: This descriptive retrospective study evaluated 2027 panoramic radiographs. The type and location of calcifications and the age and gender of patients were evaluated by two radiologists. Data were analyzed via SPSS and the Chi-square, Fisher's exact and Kappa tests were used to compare the categorical demographic variables among the groups. The confidence interval was set to $95 \%$ and $\mathrm{p}<0.05$ was considered statistically significant. Results: The prevalence of calcified stylohyoid ligament was $11.24 \%$. This value was $3.99 \%$ for tonsillolith, $1.33 \%$ for calcified carotid plaque, $0.69 \%$ for antrolith, $0.39 \%$ for calcified lymph node, $0.29 \%$ for phleboliths, and $0.19 \%$ for sialoliths. The prevalence of these conditions had no significant association with gender or age $(\mathrm{p}=0.102)$. The prevalence of bilateral calcified stylohyoid ligament, tonsillolith, and a calcified carotid plaque was significantly higher $(\mathrm{p}<0.001)$. The most prevalent type of calcified stylohyoid ligament, according to O'Carroll's classification, belonged to types $1,4,3$ and $2(\mathrm{p}<0.001)$. The most commonly observed radiographic pattern was multiple, well-defined tonsilloliths $(75.3 \%, \mathrm{p}<0.001)$. Conclusion: The prevalence of soft tissue calcifications on panoramic radiographs was relatively low in this Iranian population. The most calcifications were respectively calcified stylohyoid ligament, tonsillolith, calcified carotid plaque, antrolith, calcified lymph node, phleboliths and sialoliths. Calcified stylohyoid ligament, tonsillolith and calcified carotid plaque were more bilaterally. Thereby panoramic imaging can help in primary assessment, epidemiologic and screening evaluation of these calcifications.
\end{abstract}

Keywords: Radiography, Dental; Radiography, Panoramic; Calcinosis. 


\section{Introduction}

Heterotopic calcification refers to the deposition of calcium salts, especially calcium phosphate in a non-organized form. They are often detected accidentally. Epidemiologically, such calcifications are often seen in patients over 40 years of age, although reports regarding their occasional detection in children also exist [1,2]. Correct radiographic interpretation of these calcifications requires precise knowledge about their anatomical location, shape, number, pattern of distribution and approximate prevalence.

Calcified stylohyoid ligament refers to a ligament with over $30 \mathrm{~mm}$ of length. A calcified ligament may compress the regional nerves and the vasculature and cause symptoms such as pain; however, the majority of patients are asymptomatic. The elongated styloid process associated with some symptoms like orofacial and neck pain during swallowing, mouth opening and head rotation characterizes the Eagle's syndrome [3]. It may also compress the carotid artery and cause myocardial infarction, which is a life-threatening condition. Thus, knowledge about the anatomy and prevalence of such calcifications is imperative [4].

An antrolith is a calcified mass found in the sinus, usually maxillary. It is a rare phenomenon. Its presenting symptoms are variable and include symptoms associated with chronic sinusitis [5]. Phleboliths are intravascular thromboses that may become mineralized. In the head and neck region, these structures may indicate the presence or history of hemangioma [6]. Carotid artery calcifications are often observed in the soft tissue around the $\mathrm{C} 3$ and $\mathrm{C} 4$ cervical vertebra on radiographic images. In many patients, carotid artery calcifications are associated with a high risk of cardiovascular accidents. High blood pressure, diabetes mellitus, obesity, high level of triglycerides and cholesterol, smoking and sedentary lifestyle are among the factors that increase the risk of the formation of atherosclerotic plaques. Thus, observation of these plaques on panoramic radiographs necessitates the referral of such patients for evaluation and control of risk factors [7].

Tonsilloliths are asymptomatic, hard, round, white to yellow projections that often stick out from the tonsillar crypts and reportedly have a prevalence of $8.1 \%$ [8]. Sialoliths are homogenous or occasionally layered structures that are more commonly found in the submandibular gland. The severity of symptoms depends on the extent of the ductal obstruction, as well as the presence of a secondary infection. One study concluded that both panoramic and occlusal radiographic techniques displayed satisfactory diagnostic performance and should be considered before using a CT scan to detect submandibular sialoliths [9].

Calcified lymph nodes are opaque areas in the submandibular region at the level of the inferior border of the mandible close to the mandibular angle or between the posterior border of ramus and cervical vertebra. In case of observation on panoramic radiographs, the patients should be referred for an assessment of underlying causes. In one study evaluated 2,300 CT scans of the cervical area, of which 26 (1\%) presented lymph node calcification without determining if it was benign or malignant [10].

Panoramic radiography is the imaging modality of choice for simultaneous evaluation of both jaws in most dental treatments and screening studies due to its low patient radiation dose and low cost. Thus, considering its popularity, it seems imperative to familiarize dental clinicians with the patterns and characteristics of soft tissue calcifications on panoramic radiographs. Also, because these calcifications are often asymptomatic and are accidentally discovered in images, there is no justification for their initial evaluation with three-dimensional images except in cases where the patient is symptomatic. If the calcifications are asymptomatic, the patient is exposed to unnecessary radiation by providing three-dimensional images.

Considering the potential of soft tissue calcifications to cause pathological symptoms and the gap of information regarding their characteristics on panoramic radiographs, this study aimed to assess the prevalence and characteristics of soft tissue calcifications on panoramic radiographs. 


\section{Material and Methods}

Study Design

This descriptive retrospective study evaluated 2027 panoramic radiographs of patients presenting to the Oral and Maxillofacial Radiology Department of Hamadan School of Dentistry during 2013-2016. The radiographs had been taken for different reasons and were retrieved from the archives.

Radiographs of patients with facial deformities, pathological lesions and history of surgery or trauma were excluded [11]. Also, radiographs with difficult interpretation due to technical issues were excluded. All radiographs had been taken using a panoramic radiographic system (Planmeca ProMax, Planmeca OY, Helsinki, Finland) with the exposure settings of 5-14 $\mathrm{mA}, 62-70 \mathrm{kVp}$, and $17 \mathrm{~s}$ time, according to patient's body size.

Radiographs were observed on a 17-inch monitor with a resolution of 1280 x 1024 pixels in a dark room (L1752SE Series, LG Corporations, Seoul, South Korea) separately and independently by one oral and maxillofacial radiologists with seven years of clinical experience and a last semester radiology resident. Each viewer revised the images again within two weeks. The reliability between the two observers was estimated to be $88.3 \%$ by using the Kappa statistics, which was considered an excellent agreement. The intraclass correlation coefficient for the study was $94.3 \%$; therefore, it was acceptable.

The following factors were evaluated: calcification of stylohyoid ligament, which was measured from the base of the skull to the tip of the ligament [3]. Sizes over $30 \mathrm{~mm}$ were considered as calcified ligament. Also, the classification by Carroll [12] was used to determine the position of this ligament relative to the mandibular foramen:

- Type I: Calcification of stylohyoid ligament above the mandibular foramen (bilateral).

- Type II: Calcification of stylohyoid ligament at the level of the mandibular foramen (bilateral).

- Type III: Calcification of stylohyoid ligament below the mandibular foramen (bilateral).

- Type IV: Calcification of stylohyoid ligament with different lengths in the right and left sides, which includes all unilateral calcifications.

The prevalence of the following conditions was determined: calcified stylohyoid ligament, antrolith, phleboliths, calcified atherosclerotic plaque, tonsillolith, sialolith, and calcified lymph node. Also, single or multiple lesions, their radiographic borders and the location of tonsilloliths in the mandibular ramus were all evaluated. This information, along with age and gender of patients, number of lesions, their unilateral or bilateral nature and side of involvement were all recorded.

\section{Statistical Analysis}

The collected data from all groups were imported to Statistical Package for Social Sciences for Windows software, version 22.0 (SPSS Inc., Chicago, IL, USA). The standard descriptive methods were applied to determine the characteristics of the sample. The Chi-square test was used to compare the categorical demographic variables among the groups. Also, Fisher's exact test and Kappa test were used. The confidence interval was set to $95 \%$ and $\mathrm{p}<0.05$ was considered statistically significant.

Ethical Aspects

The study was approved in the ethics committee of Hamadan University of Medical Sciences (IR.Umsha.Rec.1397.8). 


\section{Results}

The mean age of patients was $36.83 \pm 15.46$ years. Of all, $1126(55.6 \%)$ were under 40 years and 901 $(44.4 \%)$ were over 40 years. Also, 1007 (49.7\%) patients were males and 1020 (50.3\%) were females. A total of $351(17.3 \%)$ patients had soft tissue calcification, out of which $145(41.3 \%)$ were males and $205(58.4 \%)$ were females with a mean age of $42.09 \pm 13.56$ years. Table 1 presents the frequency distribution of soft tissue calcifications along with the side of involvement. The prevalence of bilateral tonsilloliths, calcified carotid plaques and calcified stylohyoid ligaments was significantly higher compared to their unilateral occurrence $(\mathrm{p}<0.001)$. The prevalence of sialolith $(\mathrm{n}=4,0.19 \%$, in the left side in all cases) was too low to be included in statistical analysis. Tables 2 and 3 show the frequency of variables with regard to their association with age and gender of patients.

Table 1. Frequency of soft tissue calcifications and their association with the involved side.

\begin{tabular}{lclcc}
\hline \multicolumn{1}{c}{ Calcification } & $\mathbf{N}(\%)$ & Side of Involvement & $\mathbf{N}(\%)$ & p-value \\
\hline Calcified Lymph Node & $8(0.39)$ & Right & $1(12.5)$ & 0.552 \\
& & Left & $3(37.5)$ & \\
Antrolith & Bilateral & $4(50.0)$ & \\
& \multirow{2}{*}{$(4) .69)$} & Right & $7(50.0)$ & 0.111 \\
& & Left & $6(42.85)$ & \\
Carotid Plaque & Bilateral & $1(7.15)$ & \\
& \multirow{2}{*}{$27(1.33)$} & Right & $2(7.4)$ & $<0.001^{*}$ \\
& & Left & $4(14.81)$ & \\
Phleboliths & & Bilateral & $21(77.77)$ & \\
& \multirow{2}{*}{$6(0.29)$} & Right & $1(16.66)$ & 0.383 \\
& & Left & $1(16.66)$ & \\
Tonsillolith & Bilateral & $4(66.66)$ & \\
& \multirow{2}{*}{$81(3.99)$} & Right & $13(16.04)$ & $<0.001^{*}$ \\
& & Left & $15(18.51)$ & \\
Calcified Stylohyoid & $228(11.24)$ & Right & $53(65.43)$ & \\
& & Left & $21(9.21)$ & $<0.001^{*}$ \\
& & Bilateral & $43(18.85)$ & \\
\hline
\end{tabular}

*Statistically significant.

Table 2. Frequency of soft tissue calcifications based on patients' age.

\begin{tabular}{|c|c|c|c|c|}
\hline Calcification & Mean Age $( \pm S D)$ & Age & $\mathbf{N}(\%)$ & p-value \\
\hline \multirow[t]{2}{*}{ Calcified Lymph Node } & $54.27 \pm 15.14$ & $<40$ Years & $0(0.0)$ & 0.55 \\
\hline & & $>40$ Years & $8(100.0)$ & \\
\hline \multirow[t]{2}{*}{ Antrolith } & $45.21 \pm 12.22$ & $<40$ Years & $4(28.57)$ & 0.47 \\
\hline & & $>40$ Years & $10(71.42)$ & \\
\hline \multirow[t]{2}{*}{ Tonsillolith } & $46.59 \pm 13.01$ & $<40$ Years & $20(24.69)$ & 0.41 \\
\hline & & $>40$ Years & $61(75.3)$ & \\
\hline \multirow[t]{2}{*}{ Carotid Plaque } & $50.92 \pm 14.34$ & $<40$ Years & $4(14.81)$ & 0.06 \\
\hline & & $>40$ Years & $23(85.18)$ & \\
\hline \multirow[t]{2}{*}{ Phleboliths } & $38.16 \pm 11.25$ & $<40$ Years & $2(33.33)$ & 0.6 \\
\hline & & $>40$ Years & $4(66.66)$ & \\
\hline \multirow[t]{2}{*}{ Calcified Stylohyoid Ligament } & $38.96 \pm 11.46$ & $<40$ Years & $122(53.51)$ & 0.15 \\
\hline & & $>40$ Years & $106(46.49)$ & \\
\hline
\end{tabular}

Our results showed that of all calcifications, 76 (33.33\%) were type I, 70 (31.25\%) were type IV, 48 $(21.42 \%)$ were type III and $34(15.17 \%)$ were type II according to the Carroll classification. Thus, the highest 
prevalence belonged to types I, IV, III and II, respectively. The Chi-square test showed that the difference in this regard was significant $(\mathrm{p}<0.001)$.

Table 3. Association of soft tissue calcifications with gender

\begin{tabular}{llcc}
\hline \multicolumn{1}{c}{ Calcification } & \multicolumn{1}{c}{ Gender } & N (\%) & p-value \\
\hline Calcified Lymph Node & Male & $2(25.0)$ & 1.000 \\
& Female & $6(75.0)$ & \\
Antrolith & Male & $5(35.71)$ & 1.000 \\
& Female & $9(64.28)$ & \\
Tonsillolith & Male & $39(48.14)$ & 0.239 \\
& Female & $42(51.85)$ & \\
Carotid Plaque & Male & $7(25.92)$ & 0.289 \\
& Female & $20(74.07)$ & \\
Phleboliths & Male & $3(50.0)$ & 1.000 \\
& Female & $3(50.0)$ & \\
Calcified Stylohyoid Ligament & Male & $96(42.11)$ & 0.32 \\
& Female & $132(57.89)$ & \\
\hline
\end{tabular}

The mean size of stylomandibular ligament from the base of the skull to the tip of the process was $36.01 \pm 6.1 \mathrm{~mm}$ in the left and $36.83 \pm 9.6 \mathrm{~mm}$ in the right side.

All cases of antrolith were single while a percentage of calcified lymph nodes $(n=5,62.5 \%)$, carotid artery plaques $(n=20,74.07 \%)$, phleboliths $(n=1,16.66 \%)$ and sialoliths $(n=1,25 \%)$ were multiple. Regarding tonsilloliths, multiple well-defined patterns had the highest frequency, which was statistically significant $(\mathrm{n}=61,75.3 \%, \mathrm{p}<0.001)$ followed by the single type with well-defined border $(\mathrm{n}=13,16.04 \%)$, multiple with illdefined border $(n=6,7.4 \%)$ and single with ill-defined border $(n=1,1.23 \%)$. The majority of tonsilloliths were located in the middle of ramus $(n=68,85.11 \%)$ followed by the inferior part of ramus $(n=9,11.11 \%)$ and superior part of ramus ( $\mathrm{n}=4,3.78 \%)$ (Figures 1 to 3$)$.
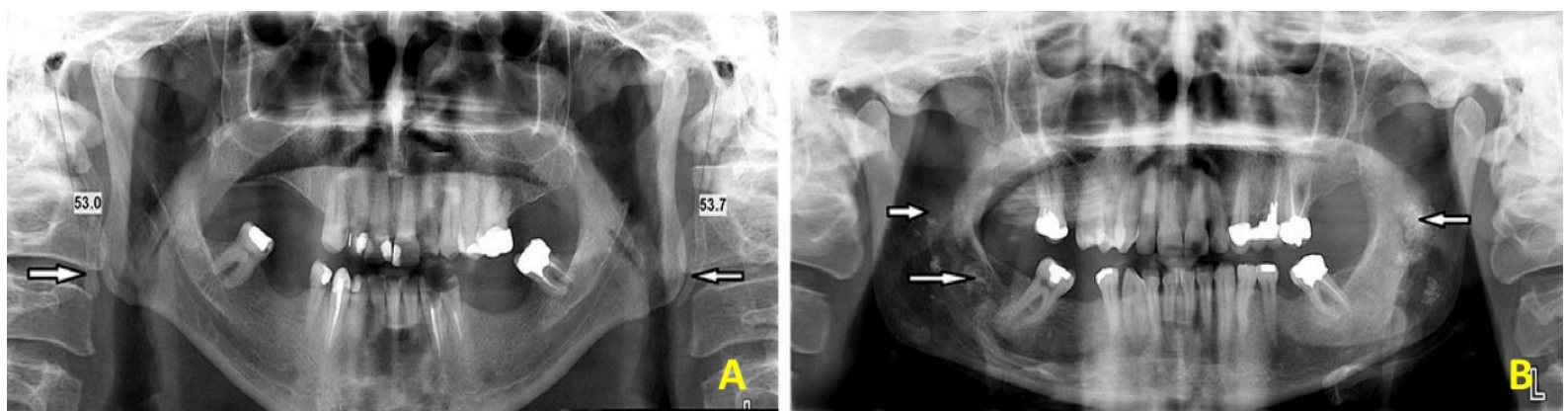

Figure 1. A) Calcified stylohyoid ligament. B) Tonsillolith.
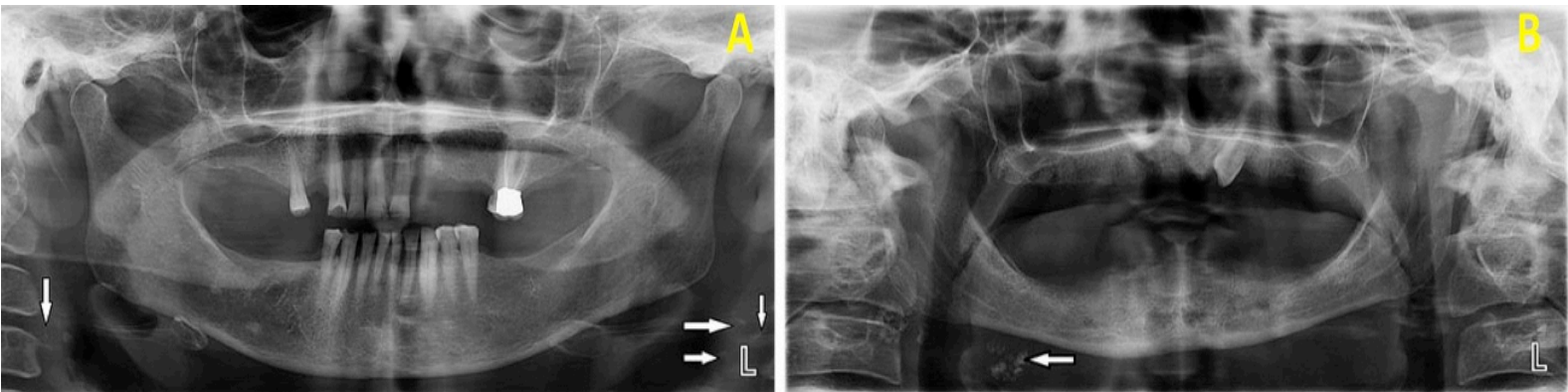

Figure 2. A) Calcified Carotid plaque. B) Calcified lymph node. 

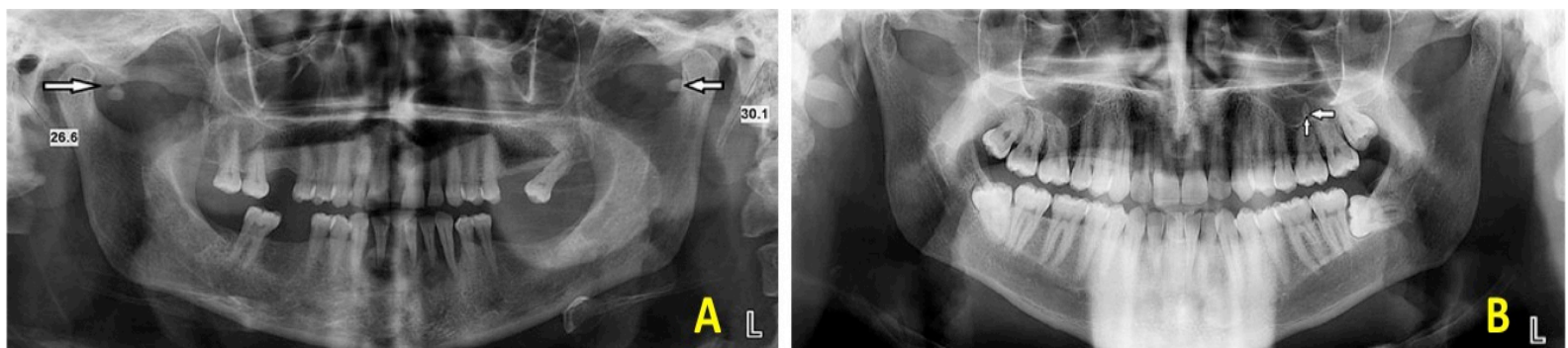

Figure 3. A) Phleboliths. B) Antrolith.

\section{Discussion}

According to the current results, of 2027 patients, 228 had calcified stylohyoid ligament with larger than $30 \mathrm{~mm}$ size (11.24\%); bilateral lesions had the highest prevalence. A high variability exists in the prevalence rates of calcified stylohyoid ligaments reported in the literature such that its prevalence varies from $4 \%$ in one study to over $84 \%$ in another study [13,14]. This rate has been reported to be $33 \%$ in Italy [15], $43.9 \%$ in Brazil [16]. High variability in its prevalence rate can be due to anatomical and racial variations, nutritional habits, lifestyle, muscle tension due to occlusal interferences [17] and different study populations and variability among the observers.

Moreover, the stylohyoid process has a medial angle, which is not well visualized on two-dimensional images. This factor, along with other inherent limitations of panoramic radiography such as image difference in magnification of different panoramic radiographic systems, distortion and superimposition, may lead to inaccuracies and underestimate the actual values.

Anatomical evaluation of human cadavers is the most accurate method for this assessment. Among different imaging modalities, computed tomography and cone-beam computed tomography are probably the most efficient modalities for assessment of the stylohyoid ligament. Some authors have considered its normal length to be $20-30 \mathrm{~mm}$ [3], while other authors stated that normal length was between $2.83 \mathrm{~cm}$ and $4.16 \mathrm{~cm}$ [18]. Therefore, the absence of a consensus regarding the standard size of this ligament also leads to high variability in the reported prevalence rates. Thus, it would be more realistic to use another method instead of reporting the size of this ligament in millimeters. Using the Carroll classification is among these methods $[12]$.

In this research, the type I calcification pattern was the most common, which was in agreement with the findings of another study [19]. In the present research, 122 (53.5\%) patients with calcified stylohyoid ligament were younger than 40 years and 132 (57.9\%) were females. The difference between the two groups older and younger than 40 years and males and females, was not significant.

Previous authors, similar to ours, reported the same prevalence rates in males and females [20]. A higher prevalence of calcification of this complex in patients between 20 to 40 years was in agreement with the results previously reported [21]; whereas, some researchers reported a higher prevalence in 50 to 59-years old $[22]$.

In our study, all of the calcifications were more common in females, although this difference was not significant for any calcification. Moreover, the majority of calcifications, except for calcified stylohyoid ligament, were more common in ages over 40 years. It was revealed that of 1042 patients, whose panoramic radiographs were evaluated, $5.7 \%$ had tonsilloliths, $0.9 \%$ had sialoliths, $5.7 \%$ had calcified carotid artery plaques, 3.6\% had calcified lymph node and 5.3\% had idiopathic osteosclerosis [23]. In total, 196 calcifications $(89.1 \%)$ were recorded in patients older than 40 years; no gender-dependent relationship could be revealed. 
Our study showed that multiple well-defined patterns were the most common $(75.3 \%, \mathrm{p}<0.001)$ followed by single-well defined (16.04\%), multiple ill-defined (7.4\%) and single ill-defined (1.23\%) patterns in tonsilloliths. In contrast to their study, our study showed that the majority of tonsilloliths were in the middle of the ramus $(85.11 \%)$ on panoramic radiographs. Also, the majority of tonsilloliths were bilateral in our study $(65.43 \%, \mathrm{p}<0.001)$. Unilateral lesions in the right side ranked second. However, a review article showed that the majority of tonsilloliths were in the right crypts [24]. However, it seems that racial and geographical differences may play a role in this respect.

In the present study, 27 patients (1.3\%) had calcified carotid plaque; out of which, $74.07 \%$ were females and $85.18 \%$ were over the age of 40 years. The overall mean age was $50.92 \pm 14.34$ years. Myocardial infarction, heart attack and temporary vision loss may occur as the result of severe calcification of the carotid artery wall. In asymptomatic patients, early detection of these calcifications and early referral of patients for further evaluations can prevent cardiovascular accidents due to obstruction [25]. The prevalence of this type of calcification is highly variable and ranges from $0.4 \%$ to $9.4 \%$, depending on the age and lifestyle of patients [26]. Carotid artery calcification was more common in females (in agreement with our findings) and was found in both unilateral and bilateral forms [26]. In our study, the majority of patients with carotid artery calcification were older than 40 years. Similarly, some authors stated that the prevalence of this calcification increases with age [27].

In general, controversy in the results of different epidemiologic studies can be due to the fact that the number of panoramic radiographs evaluated in the majority of the aforementioned studies was lower than that in our study $[15,19,23]$. The evaluation of a higher number of radiographs yields more accurate results.

CBCT images are not pretentious by magnification, distortion and overlapping of neighboring structures [28]. According to the guidelines of the American Academy of Oral and Maxillofacial Radiology, CBCT images constitute a valuable tool for the assessment of soft tissue calcifications. Considering the advantages of CBCT like current availability and usage and the high quality, it can be used to reassess the prevalence of important conditions such as soft tissue calcifications based on CBCT images [29,30]. However, it has a high patient radiation dose compared with panoramic images. Since these calcifications are often asymptomatic and not dangerous, there is no need to request a high dose radiation image for their primary evaluation.

In total, since panoramic radiography is commonly requested for dental treatments and provides a bilateral view of the jaws, it is more commonly used for assessment of prevalence and epidemiologic purpose and in some symptomatic cases, three-dimensional imaging modalities are recommended.

\section{Conclusion}

The overall prevalence of soft tissue calcifications on panoramic radiographs was relatively low in this Iranian population. The most prevalence of calcifications were, respectively: calcified stylohyoid ligament, tonsillolith, calcified carotid plaque, antrolith, calcified lymph node, phleboliths, and sialoliths. Calcified stylohyoid ligament, tonsillolith and calcified carotid plaque were more bilaterally. Thus, panoramic imaging can help in primary assessment, epidemiologic and screening evaluation of these calcifications. However, for much more accurate assessment three-dimensional imaging modalities are required.

\section{Authors' Contributions}


SS (iD) 0000-0003-2460-774X Conceptualization, Methodology, Investigation, Formal Analysis, Writing Original Draft Preparation and Writing - Review and Editing.

MF (iD) 0000-0002-4143-2112 Conceptualization, Methodology, Investigation, Formal Analysis, Writing Original Draft Preparation and Writing - Review and Editing.

BA (D) 0000-0003-3274-2650 Conceptualization, Methodology, Investigation, Formal Analysis, Writing Original Draft Preparation and Writing - Review and Editing.

All authors declare that they contributed to critical review of intellectual content and approval of the final version to be published.

\section{Financial Support}

None.

\section{Conflict of Interest}

The authors declare no conflicts of interest.

\section{References}

[1] Çağlayan F, Sümbüllü MA, Miloğlu Ö, Akgül HM. Are all soft tissue calcifications detected by cone-beam computed tomography in the submandibular region sialoliths? J Oral Maxillofac Surg 2014; 72(8):1531.e1-6. https://doi.org/10.1016/j.joms.2014.04.005

[2] Thakur JS, Minhas RS, Thakur A, Sharma DR, Mohindroo NK. Giant tonsillolith causing odynophagia in a child: a rare case report. Cases J 2008; 1(1):50. https://doi.org/10.1186/1757-1626-1-50

[3] Bruno G, De Stefani A, Balasso P, Mazzoleni S, Gracco A. Elongated styloid process: an epidemiological study on digital panoramic radiographs. J Clin Exp Dent 2017; 9(12):e1446-52. https://doi.org/10.4317/jced.54370

[4] Chuang WC, Short JH, McKinney AM, Anker L, Knoll B, McKinney ZJ. Reversible left hemispheric ischemia secondary to carotid compression in Eagle syndrome: surgical and CT angiographic correlation. AJNR Am J Neuroradiol 2007; 28(1):143-5.

[5] Manning N, Wu P, Preis J, Ojeda-Martinez H, Chan M. Chronic sinusitis-associated antrolith. ID Cases 2018; 14:e00467. https://doi.org/10.1016/j.idcr.2018.e00467

[6] Mandel L, Perrino MA. Phleboliths and the vascular maxillofacial lesion. J Oral Maxillofac Surg 2010; 68(8):1973-6. https://doi.org/10.1016/j.joms.2010.04.002

[7] Roldán-Chicano R, Oñate-Sánchez RE, López-Castaño F, Cabrerizo-Merino MC, Martínez-López F. Panoramic radiograph as a method for detecting calcified atheroma plaques. Review of literature. Med Oral Patol Oral Cir Bucal 2006; 11(3): E261-6.

[8] Bamgbose BO, Ruprecht A, Hellstein J, Timmons S, Qian F. The prevalence of tonsilloliths and other soft tissue calcifications in patients attending oral and maxillofacial radiology clinic of the University of Iowa. ISRN Dent 2014; 2014 :839635. https://doi.org/10.1155/2014/839635

[9] Kim JH, Aoki EM, Cortes AR, Abdala-Júnior R, Asaumi J, Arita ES. Comparison of the diagnostic performance of panoramic and occlusal radiographs in detecting submandibular sialoliths. Imaging Sci Dent 2016; 46(2):87-92. https://doi.org/10.5624/isd.2016.46.2.87

[10] Eisenkraft BL, Som PM. The spectrum of benign and malignant etiologies of cervical node calcification. AJR Am J Roentgenol 1999; 172(5):1433-7. https://doi.org/10.2214/ajr.172.5.10227533

[11] Garay I, Netto HD, Olate S. Soft tissue calcified in mandibular angle area observed by means of panoramic radiography. Int J Clin Exp Med 2014; 7(1):51-6.

[12] O Carroll MK. Calcification in the stylohyoid ligament. Oral Surg Oral Med Oral Pathol 1984; 58(5):617-21. https://doi.org/10.1016/0030-4220(84)90089-6

[13] Gossman JR Jr, Tarsitano JJ. The styloid-stylohyoid syndrome. J Oral Surg 1977; 35(7):555-60.

[14] Ferrario VF, Sigurtá D, Daddona A, Dalloca L, Miani A, Tafuro F, et al. Calcification of the stylohyoid ligament: incidence and morphoquantitative evaluations. Oral Surg Oral Med Oral Pathol 1990; 69(4):524-9 https://doi.org/10.1016/0030-4220(90)90390-e

[15] Gracco A, De Stefani A, Bruno G, Balasso P, Alessandri-Bonetti G, Stellini E. Elongated styloid process evaluation on digital panoramic radiograph in a North Italian population. J Clin Exp Dent 2017; 9(3):e404. https://doi.org/10.4317/jced.53450

[16] Vieira EM, Guedes OA, Morais SD, Musis CR, Albuquerque PA, Borges ÁH. Prevalence of elongated styloid process in a central Brazilian population. J Clin Diagn Res 2015; 9(9):ZC90. https://doi.org/10.7860/JCDR/2015/14599.6567

[17] Bagga MB, Kumar CA, Yeluri G. Clinicoradiologic evaluation of styloid process calcification. Imaging Sci Dent 2012; 42(3):155-61. https://doi.org/10.5624/isd.2012.42.3.155 
[18] Ledesma-Montes C, Hernández-Guerrero JC, Jiménez-Farfán MD. Length of the ossified stylohyoid complex and Eagle syndrome. Eur Arch Otorhinolaryngol 2018; 275(8):2095-100. https://doi.org/10.1007/s00405-018-5031-3

[19] İlgüy M, İlgüy D, Güler N, Bayirli G. Incidence of the type and calcification patterns in patients with elongated styloid process. J Int Med Res 2005; 33(1):96-102. https://doi.org/10.1177/147323000503300110

[20] Magat G, Ozcan S. Evaluation of styloid process morphology and calcification types in both genders with different ages and dental status. J Istanb Univ Fac Dent 2017; 51(2):29-36. https://doi.org/10.17096/jiufd.35768

[21] Rizzatti-Barbosa CM, Ribeiro MC, Silva-Concilio LR, Di Hipolito O, Ambrosano GM. Is an elongated stylohyoid process prevalent in the elderly? A radiographic study in a Brazilian population. Gerodontology 2005; 22(2):112-5. https://doi.org/10.1111/j.1741-2358.2005.00046.x

[22] Öztaş B, Orhan K. Investigation of the incidence of stylohyoid ligament calcifications with panoramic radiographs. J Investig Clin Dent 2012; 3(1):30-5. https://doi.org/10.1111/j.2041-1626.2011.00081.x

[23] Sutter W, Berger S, Meier M, Kropp A, Kielbassa AM, Turhani D. Cross-sectional study on the prevalence of carotid artery calcifications, tonsilloliths, calcified submandibular lymph nodes, sialoliths of the submandibular gland, and idiopathic osteosclerosis using digital panoramic radiography in a Lower Austrian subpopulation. Quintessence Int 2018; 22:231-42. https://doi.org/10.3290/j.qi.a39746

[24] Ram S, Siar CH, Ismail SM, Prepageran N. Pseudo bilateral tonsilloliths: a case report and review of the literature. Oral Surg Oral Med Oral Pathol Oral Radiol Endod 2004; 98(1):1 10-4. https://doi.org/10.1016/j.tripleo.2003.11.015

[25] Garoff M, Johansson E, Ahlqvist J, Jaeghagen EL, Arnerlov C, Wester P. Detection of calcifications in panoramic radiographs in patients with carotid stenosis $\geq 50 \%$. Oral Surg Oral Med Oral Pathol Oral Radiol 2014; 117(3): 38591. https://doi.org/10.1016/j.00oo.2014.01.010

[26] Alves N, Deana NF, Garay I. Detection of common carotid artery calcifications on panoramic radiographs: prevalence and reliability. Int J Clin Exp Med 2014; 7(8): 1931-9.

[27] Kumagai M, Yamagishi T, Fukui N, Chiba M. Carotid artery calcification seen on panoramic dental radiographs in the Asian population in Japan. Dentomaxillofac Radiol 2007; 36:92-6. https://doi.org/10.1259/dmfr/ 79378783

[28] Tozoğlu U, Cakur B. Evaluation of the morphological changes in the mandible for dentate and totally edentate elderly population using cone-beam computed tomography. Surg Radiol Anat 2014; 36(7):643-9. https://doi.org/10.1007/s00276-013-1241-y

[29] Scarfe WC, Farman AG. Soft tissue calcifications in the neck: maxillofacial CBCT presentation and significance. AADMRT Currents 2010; 2(2):3-15.

[30] Khojastepour L, Haghnegahdar A, Sayar H. Prevalence of soft tissue calcifications in CBCT images of mandibular region. J Dent 2017; 18(2):88-94. 